\title{
A gestão de resíduos sólidos em Parintins/AM à luz da política nacional de resíduos sólidos
}

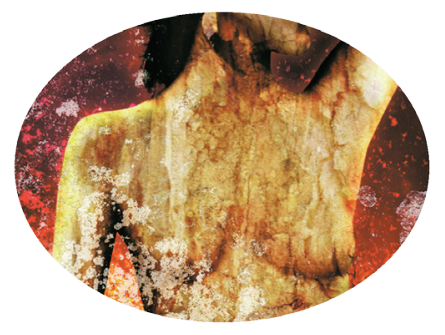

Gerson Teixeira Cardoso Filho*

\section{Resumo}

O padrão mundial de consumo da sociedade contemporânea, potencializado pelos efeitos das propagandas de marketing empresarial, nos incentiva a comprarmos cada vez mais. Muitas vezes, utensílios e materiais que ainda poderiam ser reutilizados, ou no mínimo, reciclados, são desperdiçados, seja em razão de hábitos culturais ou por falta de conhecimento sobre os impactos ambientais decorrentes. O desperdício e a disposição inadequados dos resíduos contribuem direta e indiretamente com a retirada excessiva de recursos naturais do meio ambiente e, consequentemente com a escassez desses recursos ambientais, além de determinar o acúmulo de grande quantidade de resíduos sólidos, que geram diversos tipos de impactos ambientais negativos, principalmente nos grandes centros urbanos. A problemática da gestão dos resíduos sólidos no município de Parintins/AM foi analisada mediante a comparação do estado atual da Gestão de Resíduos Sólidos adotada por esse município com os padrões e as diretrizes estabelecidas pela Política Nacional de Resíduos Sólidos - Lei n. ${ }^{\circ}$ 12.305, de 2 de agosto de 2010, e também à luz de outras legislações ambientais complementares. Os procedimentos utilizados foram pesquisa bibliográfica, consulta a órgãos gestores, bem como observação direta. Descreve-se a sistemática do tratamento dos resíduos

\footnotetext{
* Mestrando do Programa de Pós Graduação em Ciências do Ambiente e Sustentabilidade na AmazôniaPPGCASA/UFAM. Professor do Curso Técnico Subsequente de Administração do IFAM - Campus de Parintins/AM.
} 
sólidos no município desde a geração, o acondicionamento, a coleta até a destinação final. Verificou-se com este trabalho que o município de Parintins não realiza o gerenciamento integrado de resíduos sólidos. Por não realizar a coleta seletiva, despeja-se na lixeira pública, a céu aberto, todo tipo de resíduo sem o tratamento adequado, sendo estes: resíduos domiciliares, resíduos do matadouro, podas de árvores, resíduos da construção civil, entre outros. Constatou-se também que em decorrência de não haver coleta seletiva no município, a Associação dos Catadores de Lixo de Parintins - Ascalpin tem sofrido uma perda econômica considerável, visto que, com o fechamento da lixeira pública no ano de 2011, esses catadores diminuíram o volume de material reciclável coletado no município, gerando perda de receita para a referida associação, além disso, os resíduos domiciliares e até os resíduos oriundos do comércio local que são recicláveis, têm como destino a lixeira pública, contribuindo para a diminuição de sua vida útil. Ao analisar essa sistemática, observou-se a necessidade urgente da construção e implantação de uma política efetiva de resíduos sólidos para esse município, buscando, com isso, a adequação à Política Nacional de Resíduos Sólidos.

Palavras-chave: resíduos sólidos; gerenciamento; Política Nacional.

\section{Abstract}

The world pattern of consumption in contemporary society, aggravated by the effects of advertising marketing business, encourages us to buy more. Often, tools and materials that could still be reused or at least recycled are wasted, either because of cultural habits or lack of knowledge about the environmental impacts. The improper disposal of waste and residues contribute directly and indirectly related to excessive removal of natural resources of the environment and hence the scarcity of environmental resources, and to determine the accumulation of large amounts of solid waste, generating various types of negative impacts, especially in large urban centers. The problem of solid waste management in the city of Parintins/AM was analyzed by comparing the current state of the Solid Waste Management embraced by the municipality with the standards and guidelines established by the National Solid Waste - Law n. 12,305 of 2 August 2010 and also in light of other complementary environmental laws. The procedures used were literature review, consultation 
with governing bodies, as well as direct observation. We describe the systematic treatment of solid waste in the city since it's: generation, packaging, collection and disposal. Noted in this work, that the city of Parintins not realize the integrated management of solid waste. Due to the fact that this city does not perform the selective collection in public dumps, all kinds of waste without proper treatment, such as: household waste, slaughterhouse waste, tree pruning, construction waste, among others. It was also found that due to not do garbage collection at the municipality, the Association of Garbage Collectors in Parintins - Ascalpin has suffered a substantial economic loss, since the closing of the public trash can in the year 2011, these scavengers decreased the volume of recyclable material collected in the county, generating revenue loss for that association, besides, household waste and even the waste from the local businesses that have recyclable trash destined for the public, contributing to the reduction of lamp life. In this systematic review, there was urgent need for the construction and implementation of an effective policy of solid waste to this city, seeking thereby to fitness for the National Solid Waste.

Keywords: Solid Waste, Management, National Policy.

\section{Introdução}

O padrão mundial de consumo da sociedade contemporânea incentivanos muitas vezes a comprarmos os mais variados bens e produtos sem a necessidade real de os consumir. Somos muitas vezes incentivados a trocar de carro, de computador, de televisão, de geladeira, de roupas etc., sem a necessidade de comprá-los, assim, vamos às compras mais pelo prazer que ela irá nos proporcionar do que pela real necessidade de compra.

Muitos desses bens e produtos, que são substituídos por novos bens e produtos, poderiam ser reutilizados ou até mesmo reciclados, entretanto são desperdiçados e acabam tendo como destino a lixeira pública da cidade.

O município de Parintins possui um pouco mais de cem mil habitantes e, segundo consulta, a Semosp, este gera diariamente entre 65 a 75 toneladas de resíduos sólidos, sendo estes: resíduos domiciliares, resíduos sólidos de limpeza pública, resíduos de serviços de saúde, resíduos da construção civil, resíduos agrossilvopastoris e outros. Em períodos do ano referentes ao calendário de 
festividades, como: no Festival Folclórico de Parintins - ocorrido anualmente no último final de semana do mês de junho, período de carnaval e no período de festas de fim de ano, verifica-se que a geração de resíduos sólidos no município cresce vertiginosamente e atinge picos acima de 75 toneladas/dia, o que evidencia a relação do aumento do consumo com a produção de resíduos na cidade, sua posterior destinação de rejeitos e até de materiais recicláveis na lixeira pública da cidade.

Atualmente, está em fase de implantação pela Secretaria de Desenvolvimento Sustentável e Meio Ambiente de Parintins - Sedema o projeto para pôr em prática a coleta seletiva no município de Parintins. Com a implantação bem-sucedida dessa prática, o resíduo domiciliar coletado diariamente e que hoje está tendo como destinação final a lixeira pública de Parintins, deverá diminuir, visto que esses resíduos são misturados com diversos materiais recicláveis como: o plástico, o vidro, o papelão, as garrafas PET de refrigerantes, o papel, as latinhas de alumínio, dentre outros resíduos, que têm valor comercial e que podem ser reciclados para serem utilizados como insumos dentro de novos processos produtivos.

A Associação de Catadores de Lixo de Parintins - Ascalpin é a principal responsável por realizar a coleta de matérias recicláveis no município. Com mais de 70 associados cadastrados, hoje realiza suas atividades apenas com 25 associados, em função do fechamento da lixeira pública em 2011. Com a proibição de acesso à lixeira, houve uma diminuição dos materiais recicláveis coletados, pois os associados não mais puderam entrar na área para catar os materiais recicláveis. Embora o fechamento da lixeira, por determinação do poder público municipal, tenha tido a finalidade de resguardar a saúde dos catadores, essa decisão acarretou em uma diminuição na receita da associação e alguns desses associados se viram obrigados a procurar outra forma de subsistência, abandonando suas atividades na referida associação.

A problemática na Gestão dos Resíduos Sólidos mostra-se evidente em todo o território brasileiro. Com a finalidade de dispor sobre princípios, objetivos e instrumentos, bem como sobre as diretrizes relativas à gestão integrada e gerenciamento de resíduos sólidos, foi instituída a Lei n..$^{\circ}$ 12.305/2010, referente à Política Nacional de Resíduos Sólidos - PNRS, estabelecendo um padrão normalizador na gestão de resíduos sólidos no Brasil.

Como referencial teórico, buscou-se realizar uma breve contextualização 
sobre a questão do consumo e a sua relação com a produção de resíduos, bem como uma contextualização da gestão dos resíduos sólidos no município de Parintins, descrevendo a sistemática do tratamento dos resíduos sólidos em Parintins, desde sua geração, acondicionamento, coleta e destinação final. Retratou-se a importância do trabalho da Ascalpin, na coleta de matérias recicláveis no município e, em seguida, buscou-se abordar aspectos da política nacional de resíduos sólidos que fossem capazes de agregar significativa contribuição ao debate para a efetiva gestão dos resíduos sólidos no município de Parintins.

Utilizaram-se como procedimentos metodológicos os seguintes elementos: pesquisa bibliográfica, consulta aos órgãos gestores e a Ascalpin, bem como observação direta.

Por último, apresentam-se as considerações finais e algumas sugestões que visam o aprimoramento das práticas de gestão relacionadas aos resíduos sólidos no referido município.

\section{O consumo e a geração de resíduos sólidos}

O padrão mundial de consumo da sociedade contemporânea, potencializado pelos efeitos das propagandas de marketing empresarial, nos incentiva a comprarmos cada vez mais. Muitas vezes, utensílios e materiais que ainda poderiam ser reutilizados, ou no mínimo, reciclados, são desperdiçados, seja em razão de hábitos culturais ou por falta de conhecimento sobre os impactos ambientais decorrentes.

Oriunda da evolução do processo de industrialização, nossa civilização chegou a um patamar de produção muito elevado. Nosso ritmo intenso de consumo, com a exploração, muitas vezes predatória de recursos naturais, tem se refletido em impactos ambientais diversos e gerado a escassez de recursos naturais.

O ritmo de consumo, o desperdício e a disposição final inadequada dos resíduos têm contribuído direta e indiretamente com o acúmulo de grande quantidade de resíduos sólidos, que geram diversos tipos de impactos ambientais negativos, principalmente nos grandes centros urbanos, reflexo das contradições de um desenvolvimento industrial e tecnológico nunca visto na história da humanidade, típico dessa sociedade de consumo. 


\section{A gestão de resíduos sólidos em Parintins}

Segundo a PNRS, os administradores públicos municipais são os responsáveis legais pela gestão dos resíduos sólidos nos municípios. Conforme a Sedema, hoje, o município de Parintins/AM não tem condições financeiras para elaborar e implantar um plano de gerenciamento de resíduos sólidos, nos moldes da Lei n. ${ }^{\circ}$ 12.305/2010, por esse plano demandar alto investimento financeiro.

O município de Parintins está elaborando o Plano de Saneamento Básico e o Plano Municipal de Gestão Integrada de Resíduos Sólidos de acordo com as normas da Lei n. ${ }^{\circ}$ 12.305/2010, uma parceria da Secretaria Estadual de Meio Ambiente e Desenvolvimento Sustentável - SDS com a Associação Amazonense de Municípios - AAM. A proposta desse programa é "estruturar e coordenar ações que conduzam à solução dos problemas de saneamento básico no Estado do Amazonas" (PLAMSAN, 2012).

Nesse programa, a construção dos planos municipais de gestão do saneamento e de resíduos sólidos é realizada de forma articulada, para viabilizar no futuro a elaboração e a implantação dos respectivos projetos técnicos e de engenharia.

A Política Nacional de Resíduos Sólidos incentiva que os municípios trabalhem em consórcio com vistas à elaboração e implantação de planos intermunicipais de gestão de resíduos sólidos; entretanto, no Estado do Amazonas, fica inviável trabalhar com soluções consorciadas por conta das questões geográficas e logísticas peculiares da região, o que acarretariam custos elevados.

\section{A sistemática do tratamento de resíduos sólidos em Parintins}

O município de Parintins possui mais de cem mil habitantes, e todo o resíduo sólido urbano produzido tem como destinação final a lixeira pública da cidade, localizada no bairro de Djard Vieira, ao lado da Universidade do Estado do Amazonas - UEA, que, hoje, tornou-se uma área residencial. 


\section{Geração e acondicionamento de resíduos sólidos}

Segundo consulta à Secretaria Municipal de Obras e Serviço Público Semosp, o município de Parintins produz entre 65 a 75 toneladas por dia de resíduos sólidos, sendo eles divididos em: resíduos domiciliares, resíduos sólidos de limpeza pública, resíduos de serviços de saúde, resíduos da construção civil, resíduos agrossilvopastoris, entre outros.

A maior parte dos resíduos gerados é oriunda dos lares dos munícipes, e são em maior parte composto por resíduos orgânicos, acondicionados em sacos plásticos e depositados em horário específico estabelecido pela Semosp e devem ser dispostos em local apropriado para a coleta diária realizada por parte da empresa responsável pela coleta de resíduos na cidade - a Tercom.

\section{Coleta e disposição final de resíduos sólidos}

O município de Parintins ainda não opera um sistema de coleta seletiva, no entanto este se encontra em fase de implantação. Assim, os resíduos domiciliares coletados diariamente, que são compostos dos mais diversos tipos de resíduos, como: materiais orgânicos, vidros, garrafas PET de refrigerantes, latas de alumínio, caixas de papelão, latas de sardinha, de seleta, copos de iogurtes, resíduos oriundos dos banheiros das residências, como: papel higiênico, absorventes, recipientes plásticos de xampu etc. estão tendo como destino final a lixeira pública da cidade.

Verifica-se que esses resíduos não estão tendo nenhum tipo de tratamento adequado antes de serem despejados na lixeira, quanto a segregação de materiais considerados como rejeitos daqueles materiais que poderiam ser comercializados, os chamados materiais recicláveis.

A coleta e a disposição final dos resíduos sólidos no município de Parintins são realizadas pela da empresa Tercom, que foi a vencedora do procedimento licitatório para essa finalidade. Essa empresa tem a responsabilidade de coletar todos os tipos de resíduos no município, bem como realizar a disposição final deles na lixeira pública de Parintins, que é denominada hoje pelos gestores do município de aterro controlado.

No que tange ao serviço de coleta de resíduos domiciliares, a Tercom realiza no município a coleta regular de resíduos diariamente, e atende, hoje, 
residências e comércios, atuando em 97\% da área urbana do município de Parintins, coletando todos os tipos de resíduos postos nas lixeiras residenciais. A destinação final se dá em uma área específica da lixeira pública e após a compactação dos resíduos, é jogado sobre eles grande quantidade de areia para que esses resíduos não atraiam urubus.

Quanto à coleta de resíduos de serviços de saúde, esta é realizada diariamente, com caminhão próprio e destina-se a coletar apenas resíduos hospitalares. A coleta desses materiais passa por todos os postos de saúde e também pelos dois hospitais localizados no município. A destinação final desses resíduos se dá em local próprio. Para essa finalidade são construídas células específicas para a disposição final desses resíduos.

A coleta das podas e capinas na cidade é realizada de forma sazonal, dada a demanda do município. O munícipe, antes de efetuar serviço de capina e podas em sua residência, deve entrar em contato com a Semosp e esta marcar uma data para coletar esses resíduos na residência demandante. O mesmo procedimento deve ser feito para ser realizado o serviço de coleta de entulho e de resíduos da construção civil.

Os resíduos oriundos do matadouro municipal de Parintins são coletados diariamente, em caminhão próprio, obedecendo a uma sistemática peculiar de disposição final na lixeira pública municipal. Este é incinerado e compactamse as cinzas dos resíduos com areia.

\section{O risco aviário e o fechamento do aeroporto para voos diurnos}

Em 2010, após ação civil pública ingressada no Ministério Público Federal, referente ao processo n. ${ }^{\circ}$ 7835-28.2010.4.01.320 - Classe 7.100 Ações Civis Públicas. O juiz de direito Dr. Dimas da Costa Braga decidiu:

1 - A imediata paralisação das atividades no aeródromo de Parintins, haja vista o risco inerente de um acidente/incidente aéreo, por tempo indeterminado, até que sejam cumpridos os pedidos abaixo relacionados e que fique constatada pela Anac, Cenpinpa, Ipaam e Ibama a redução do perigo aviário em níveis aceitáveis;

2 - O cumprimento das determinações abaixo, de forma permanente, pelo município de Parintins e de acordo com as recomendações técnicas do 
Ipaam.

- Apresentar Plano de Operação de Monitoramento do Lixão;

- Transferir o ponto de descarregamento de lixo, que atualmente se encontra próximo da via de acesso, para a parte interna do lixão, estabelecendose uma via secundária de acesso como forma de melhorar, aproveitar e ordenar o espaço do terreno e facilitar as manobras do carro de lixo;

- Realizar no lixão a deposição separada dos resíduos, de acordo com a origem e adequada com a formação da massa de resíduos, facilitando a operação de recobrimento, devendo os resíduos vegetais ter um local específico para deposição;

- Abrir valas, na parte interna do lixão, para a deposição dos resíduos de frigoríficos, e de serviços de saúde, separados do local destinado a resíduos domiciliares, fazer o imediato recobrimento daqueles resíduos, logo após o descarregamento dos veículos;

- Elaborar e apresentar ao Ibama um plano de manejo de aves segundo as instruções definidas por este Instituto;

- Realizar Campanha de Educação Ambiental.

Até a presente data, junho de 2012, o aeroporto municipal de Parintins, denominado Aeroporto Júlio Belém, encontra-se fechado por conta do município não conseguir atender as determinações do juiz acima citadas. $\mathrm{O}$ fechamento é consequência do perigo de risco aviário e pelo município não conseguir realizar uma gestão eficiente de resíduos sólidos. Pela proximidade do aeroporto com a lixeira pública, distante há pouco mais de $4 \mathrm{~km}$, o aparecimento de urubus, quero-queros, acural, e outras aves que são atraídas para as áreas próximas do aeroporto impede que haja voos diurnos no município, pois há o perigo de que qualquer desses pássaros colida com uma turbina de aeronave nas regiões do aeroporto municipal.

Como Parintins é uma ilha e sua extensão territorial é limitada, faz-se necessário que a construção do aterro sanitário se dê fora dos limites urbanos da cidade, por essa razão, o aterro será construído na região da Vila Amazônia, oriundo de recursos da Política Nacional de Resíduos Sólidos.

No dia 26 de fevereiro de 2011, o superintendente da CPRM, Marcus Antônio Oliveira, o Sr. José Luiz Marmos, supervisor de Gestão Territorial 
- CPRM, Alzenilson Aquino, subsecretário de Meio Ambiente de Parintins, e lideranças comunitária da Vila Amazônia realizaram visitas na área da futura instalação do Aterro Sanitário de Parintins (Mapa 1) para uma primeira avaliação visual dos técnicos, de acordo com as coordenadas tomadas pelos técnicos da CPRM no campo com GPS, a área tem em torno de 1.400 metros x 350 metros, ou seja, em torno de 49 hectares. A distância da área até o centro da pista do aeroporto é de $17 \mathrm{~km}$.

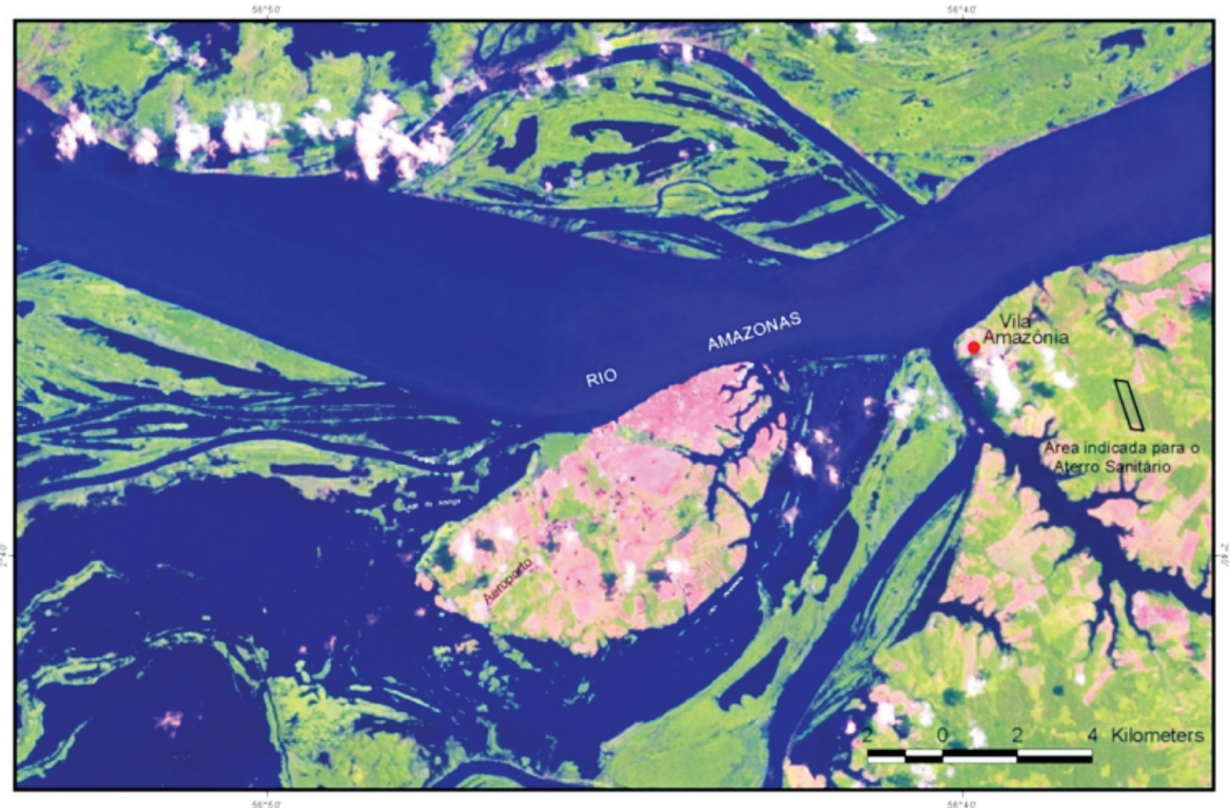

Mapa 1 - Cidade de Parintins com a área da futura instalação do aterro sanitário Fonte: Relatório Técnico das Atividades Realizadas na Lixeira de Parintins, Sedema, 2011.

\section{A associação dos catadores de lixo de Parintins - Ascalpin}

A Associação dos Catadores de Lixo de Parintins - Ascalpim realiza suas atividades há mais de dez anos em Parintins.

Com mais de 70 associados registrados, sendo em sua maioria composta de mulheres, a associação realiza a coleta de materiais recicláveis na cidade de Parintins. Entretanto, no ano de 2011, com o fechamento da lixeira pública de Parintins, local onde era coletada a maior quantidade de materiais recicláveis 
pela associação, houve uma diminuição significativa de receita pela associação, o que levou alguns associados a abandonarem suas atividades e demandarem por novos meios de subsistência.

Atualmente, apenas 25 associados estão realizando a atividade de coleta de materiais pelas ruas e comércios da cidade de Parintins.

A Ascalpin coleta os seguintes materiais para fins de comercialização em Manaus:

- Papelão, o preço de venda é de R\$ 0,20 o quilo;

- Garrafa PET de plástico, o preço de venda é de R \$ 0,80 o quilo;

- Plásticos de cadeiras, de mesas, recipiente de xampu, copos plásticos de cerveja, o preço de venda é de $\mathrm{R} \$ 0,35$ o quilo;

- Grades plásticas de cerveja, recipientes de amaciante, o preço de venda é de $\mathrm{R} \$ 0,50$ o quilo.

- Latinhas de alumínio, o preço de venda é de R \$2,00 o quilo, entretanto é raríssimo encontrar na lixeira, visto seu preço de revenda.

Existem outros tipos de materiais recicláveis, como: papel, vidro, isopor etc. que poderiam ser coletados pela Ascalpin, entretanto esses materiais não têm comprador em Parintins e nem em Manaus, então nem são coletados pela associação, tendo como destinação final a lixeira pública de Parintins.

Após o fechamento da lixeira pública, a Ascalpin consegue vender mensalmente, em média, apenas 13 toneladas de papelão, uma tonelada de PET de refrigerantes e $250 \mathrm{~kg}$ de plásticos.

Antes do fechamento da lixeira pública, a Ascalpin conseguia vender mensalmente 14 toneladas de papelão, 3,2 toneladas de PET de refrigerantes e 1,5 tonelada de plásticos.

Pode-se dizer que os catadores vivem hoje da coleta do papelão e, segundo eles, a coleta do PET de refrigerante faz muita falta na renda mensal.

Os 25 associados que realizam seu trabalho diariamente estão recebendo mensalmente a quantia aproximada de $\mathrm{R} \$ 100,00$, descontadas as despesas de transporte. Os associados, em sua maioria, são beneficiários do Programa Bolsa Família, do governo federal, e paralelamente às atividades realizadas na associação, alguns associados realizam as seguintes atividades: realizam transporte de cargas e passageiros em triciclos, outros realizam a atividade de 
servente de pedreiro e algumas catadoras vão trabalhar como domésticas em residências para complementarem sua renda.

A Prefeitura Municipal de Parintins cede um caminhão para transportar da Ascalpin para a balsa todo o material que irá para venda em Manaus.

Quando a lixeira pública foi fechada há mais de um ano, a promessa da administração pública foi a de implantar a coleta seletiva no município. Até hoje a associação espera por isso.

\section{A Política Nacional de Resíduos Sólidos (PNRS) - Lei n. ${ }^{\circ}$ 12.305/2010}

A Lei n. ${ }^{\circ}$ 12.305, de 2 de agosto de 2010, institui a Política Nacional de Resíduos Sólidos. Em seu art. 4. ${ }^{\circ}$ a PNRS reúne:

O conjunto de princípios, objetivos, instrumentos, diretrizes, metas e ações adotados pelo Governo Federal, isoladamente ou em regime de cooperação com Estados, Distrito Federal, Municípios ou particulares, com vistas à gestão integrada e ao gerenciamento ambientalmente adequado dos resíduos sólidos.

No art. 6. $^{\circ}$, destacam-se os seguintes princípios da PNRS:

I - prevenção e a precaução;

II - o poluidor-pagador e o protetor-recebedor;

III - visão sistêmica, na gestão dos resíduos, que considere as variáveis ambientais, social, cultural, econômica, tecnológica e de saúde pública;

VI - a cooperação entre as diferentes esferas do poder público, o setor empresarial e demais segmentos da sociedade;

VIII - o reconhecimento do resíduo sólido reutilizável e reciclável como um bem econômico e de valor social, gerador de trabalho e renda e promotor de cidadania.

Elencam-se no art. . $^{\circ}$ alguns objetivos contidos na Política Nacional de Resíduos Sólidos:

I - proteção da saúde pública e da qualidade ambiental; 
II - não geração, redução, reutilização, reciclagem e tratamento dos resíduos sólidos, bem como disposição final ambientalmente adequada dos rejeitos;

III - estímulo à adoção de padrões sustentáveis de produção e consumo de bens e serviços;

VI - incentivo à indústria da reciclagem, tendo em vista fomentar o uso de matérias-primas e insumos derivados de materiais recicláveis e reciclados;

VII - gestão integrada de resíduos sólidos;

VIII - articulação entre as diferentes esferas do poder público, e destas com o setor empresarial, com vistas à cooperação técnica e financeira para a gestão integrada de resíduos sólidos;

XII - integração dos catadores de materiais reutilizáveis e recicláveis nas ações que envolvam a responsabilidade compartilhada pelo ciclo de vida dos produtos.

Quanto à gestão de resíduos sólidos, voltada à responsabilidade dos municípios, o art. 18, da PNRS, normatiza que:

A elaboração de plano municipal de gestão integrada de resíduos sólidos, nos termos previstos por esta Lei, é condição para o Distrito Federal e os Municípios terem acesso a recursos da União, ou por ela controlados, destinados a empreendimentos e serviços relacionados à limpeza urbana e ao manejo de resíduos sólidos, ou para serem beneficiados por incentivos ou financiamentos de entidades federais de crédito ou fomento para tal finalidade.

Dessa forma, os municípios brasileiros deverão se adequar às normas estabelecidas pela PNRS, para poderem ser beneficiados por incentivos ou financiamentos para elaborarem o Plano Municipal de Gestão Integrada de Resíduos Sólidos.

No que tange à elaboração e ao conteúdo do Plano Municipal de Gestão Integrada de Resíduos Sólidos, o art. 19, da política nacional, regulamenta que este deve ter o seguinte conteúdo mínimo:

I - diagnóstico da situação dos resíduos sólidos gerados no respectivo 
território, contendo a origem, o volume, a caracterização dos resíduos e as formas de destinação e disposição final adotadas;

II-identificação de áreas favoráveis para disposição final ambientalmente adequada de rejeitos, observado o plano diretor de que trata o $\int 10^{\circ}$ do art. 182, da Constituição Federal, e o zoneamento ambiental, se houver;

III - identificação das possibilidades de implantação de soluções consorciadas ou compartilhadas com outros Municípios, considerando, nos critérios de economia de escala, a proximidade dos locais estabelecidos e as formas de prevenção dos riscos ambientais;

IV - identificação dos resíduos sólidos e dos geradores sujeitos a plano de gerenciamento específico nos termos do art. 20 ou a sistema de logística reversa na forma do art. 33, observadas as disposições desta Lei e de seu regulamento, bem como as normas estabelecidas pelos órgãos do Sisnama e do SNVS;

$\mathrm{V}$ - procedimentos operacionais e especificações mínimas a serem adotados nos serviços públicos de limpeza urbana e de manejo de resíduos sólidos, incluída a disposição final ambientalmente adequada dos rejeitos e observada a Lei n. ${ }^{\circ}$ 11.445, de 2007;

VI - indicadores de desempenho operacional e ambiental dos serviços públicos de limpeza urbana e de manejo de resíduos sólidos;

VII - regras para o transporte e outras etapas do gerenciamento de resíduos sólidos de que trata o art. 20, observadas as normas estabelecidas pelos órgãos do Sisnama e do SNVS e demais disposições pertinentes da legislação federal e estadual;

VIII - definição das responsabilidades quanto à sua implementação e operacionalização, incluídas as etapas do plano de gerenciamento de resíduos sólidos a que se refere o art. 20 a cargo do poder público;

IX - programas e ações de capacitação técnica voltados para sua implementação e operacionalização;

$\mathrm{X}$ - programas e ações de educação ambiental que promovam a não geração, a redução, a reutilização e a reciclagem de resíduos sólidos;

XI - programas e ações para a participação dos grupos interessados, em especial das cooperativas ou outras formas de associação de catadores de materiais reutilizáveis e recicláveis formadas por pessoas físicas de baixa renda, se houver; 
XII - mecanismos para a criação de fontes de negócios, emprego e renda, mediante a valorização dos resíduos sólidos;

XIII - sistema de cálculo dos custos da prestação dos serviços públicos de limpeza urbana e de manejo de resíduos sólidos, bem como a forma de cobrança desses serviços, observada a Lei n..$^{\circ} 11.445$, de 2007;

XIV - metas de redução, reutilização, coleta seletiva e reciclagem, entre outras, com vistas a reduzir a quantidade de rejeitos encaminhados para disposição final ambientalmente adequada;

XV - descrição das formas e dos limites da participação do poder público local na coleta seletiva e na logística reversa, respeitando o disposto no art. 33, e de outras ações relativas à responsabilidade compartilhada pelo ciclo de vida dos produtos;

XVI - meios a serem utilizados para o controle e a fiscalização, no âmbito local, da implementação e operacionalização dos planos de gerenciamento de resíduos sólidos de que trata o art. 20 e dos sistemas de logística reversa previstos no art. 33;

XVII - ações preventivas e corretivas a serem praticadas, incluindo programa de monitoramento;

XVIII - identificação dos passivos ambientais relacionados aos resíduos sólidos, incluindo áreas contaminadas, e respectivas medidas saneadoras;

XIX - periodicidade de sua revisão, observado prioritariamente o período de vigência do plano plurianual municipal.

$\int 1^{\circ}$ - O plano municipal de gestão integrada de resíduos sólidos pode estar inserido no plano de saneamento básico previsto no art. 19 da Lei n. ${ }^{\circ}$ 11.445, de 2007, respeitado o conteúdo mínimo previsto nos incisos do caput e observado o disposto no $\ 2 .^{\circ}$, todos deste artigo.

Conforme o art. 25, da PNRS, cabe ao poder público, ao setor empresarial e à coletividade a responsabilidade pela efetividade das ações voltadas para assegurar a observância da Política Nacional de Resíduos Sólidos, das diretrizes e demais determinações estabelecidas nessa lei e em seu regulamento.

Complementando o artigo anterior, o art. 26, da mesma lei, diz que: o titular dos serviços públicos de limpeza urbana e de manejo de resíduos sólidos é o responsável pela organização e prestação direta ou indireta desses serviços, observados o respectivo plano municipal de gestão integrada de 
resíduos sólidos, a Lei n. ${ }^{\circ}$ 11.445, de 2007, e as disposições dessa lei e seu regulamento.

\section{Considerações finais}

Muitos são os desafios a serem enfrentados em busca de uma forma eficiente de realizar o gerenciamento de resíduos sólidos em Parintins, de forma a atender aos princípios e objetivos da Política Nacional de Resíduos Sólidos.

A partir da identificação da sistemática do tratamento dos resíduos sólidos no município, desde a sua geração, acondicionamento, coleta e destinação final, foi possível constatar que é inadequado o procedimento realizado para destinação final dos resíduos sólidos.

A lixeira pública é um problema do gestor do município e um transtorno para a população, principalmente a da área residencial vizinha à lixeira. Em períodos de chuva o chorume exala um odor forte próximo à área da lixeira, causando grande incômodo à população.

O fechamento do aeroporto para voos diurnos no município tem gerado um impacto na economia local, visto que a cidade, por ser turística, deixa de receber um maior número de voos diários o que causa prejuízo para a cadeia hoteleira, para bares e restaurantes, para a companhia aérea que realiza menos voos diários e vende menos passagens, e para os munícipes, pois, com a diminuição de voos diários, as passagens de avião ficam mais caras.

A futura instalação do aterro sanitário na região da Vila Amazônia, distante do aeroporto de Parintins $17 \mathrm{~km}$, deverá ter um grande custo logístico, uma vez que o acesso de Parintins até a Vila Amazônia se dá por transporte fluvial, com um tempo médio de trinta minutos.

Quanto a catadores associados da Ascalpin, fica claro que o município está muito longe de atender aos princípios e objetivos da Política Nacional de Resíduos Sólidos, uma vez que não está dando nenhum apoio financeiro para a Ascalpin se estruturar, de forma a realizar a integração da associação no processo de coleta de resíduos.

Vale destacar que a média de 15 toneladas de materiais recicláveis coletados pela associação corresponde a $0,77 \%$ de todos os resíduos coletados pela Tercom, cujo contrato de coleta e destinação final dos resíduos gira em 
torno de $\mathrm{R} \$ 280$ mil reais mensais. Se fosse pago à Ascalpin o valor proporcional dos resíduos sólidos que ela evita que vá para a lixeira, a prefeitura deveria pagar a essa associação o valor mensal de $\mathrm{R} \$ 2.153,85$, o que não seria nenhum favor feito à Ascalpin, visto que no art. 6. ${ }^{\circ}$, inciso II, da Política Nacional de Resíduos Sólidos, fala-se do poluidor-pagador e do protetor-recebedor.

A Ascalpin poderia recolher uma quantidade muito maior de materiais recicláveis se hoje estivesse funcionando a prática da coleta seletiva, o que aumentaria a receita da associação de catadores e diminuiria a quantidade de resíduos que teriam como destino a lixeira pública de Parintins, contribuindo com o aumento do tempo útil da lixeira.

Dessa forma, considerando-se o que dispõe a Política Nacional de Resíduos Sólidos e o que foi exposto sobre a gestão de resíduos sólidos no município de Parintins, fica clara a distância entre o real e o ideal no que diz respeito ao gerenciamento de resíduos sólidos no município e fica evidente a necessidade de uma política efetiva de resíduos que se amolde à Política Nacional.

\section{Referências}

AAM. Associação Amazonense de Municípios. Programa de Apoio à Elaboração dos Planos Municipais de Saneamento e de Gestão Integrada de Resíduos Sólidos dos Municípios do Estado do Amazonas.

BRASIL. Constituição da República Federativa do Brasil. 5 de outubro de 1988. . Lei n. 9.795, de abril de 1999. Dispõe sobre a educação ambiental e institui a Política Nacional de Educação Ambiental. Diário Oficial da União, Brasília, 28 de abril de 1999.

- Lei n. 11.445, de 5 de janeiro de 2007. Estabelece diretrizes nacionais para o saneamento. Diário Oficial da União, Brasília, 8 de janeiro de 2007.

. Lei n. 12.305, de 2 de agosto de 2010. Institui a Política Nacional de Resíduos Sólidos; altera a Lei n. 9.605, de 12 de fevereiro de 1998; e dá outras providências. Diário Oficial da União, Brasília, 2 de agosto de 2010.

. Decreto n. ${ }^{\circ}$.404, de 23 de dezembro de 2010. Regulamenta a Lei 
da Política Nacional de Resíduos Sólidos, de 2 de agosto de 2010, e dá outras providências. Diário Oficial da União, Brasília, 23 de dezembro de 2010.

PARINTINS. Lei n.o 001/2004. Lei Orgânica do Município de Parintins, de 30 de março de 2004.

- Lei n. 009/2005. Autoriza o Município de Parintins a cobrar multa por colocação de lixo não domiciliar em via pública, e dá outras providências. Parintins, 18 de abril de 2005.

. Lei n. ${ }^{\circ}$ 375/2006. Regulamenta o Plano Diretor do Município de Parintins e estabelece diretrizes gerais da politica urbana e rural do município, e dá outras providências. Parintins, 6 de outubro de 2006.

- Lei n.o 387/2006. Institui o Código Ambiental do Município de Parintins, e dá outras providências. Parintins, 22 de dezembro de 2006.

. Lei n.o 407/2007. Institui o novo Código de Posturas do Município de Parintins, e dá outras providências. Parintins, 10 de dezembro de 2007.

PLAMSAN. Programa de Apoio à Elaboração dos Planos Municipais de Saneamento Básico e de Gestão Integrada dos Resíduos Sólidos dos Municípios do Estado do Amazonas. Disponível em <http://www.plamsan.org.br/publicacoes.php> Acesso em: 7/6/2012.

SEDEMA, Secretaria Municipal de Desenvolvimento Sustentável e Meio Ambiente. Relatório Técnico das Ações Desenvolvidas na Lixeira Pública e Aeroporto Júlio Belém em Parintins. Prefeitura Municipal de Parintins. Parintins, março de 2011.

- Secretaria Municipal de Desenvolvimento Sustentável e Meio Ambiente. Relatório Técnico das Atividades Realizadas na Lixeira de Parintins. Prefeitura Municipal de Parintins. Parintins, agosto de 2011. 